\title{
ما أهمله ابن فارس في معجم مقاييس اللغة
}

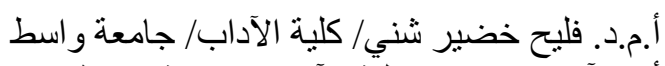
أ. د. آلاء عبد نعيم/ كلية الآداب/ جامعة واسط جالئ

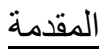

لقد قام المعجم العربيّ على أمرين مهمين هما ؛ الجمع و التَّأليف ، وأَيٌْ خلل في أحد هذين الأمرين سيجعل المعجم

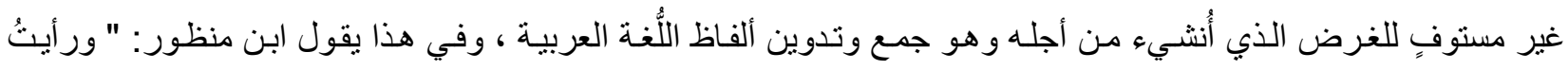

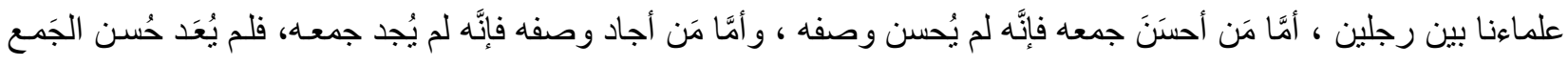

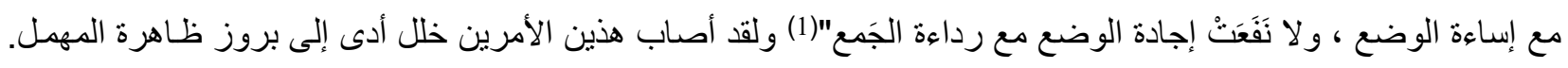

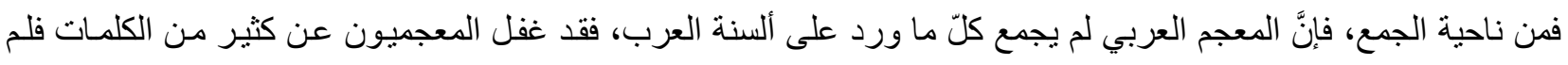

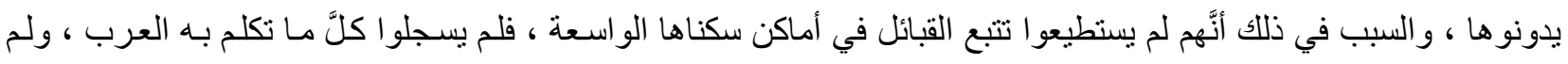

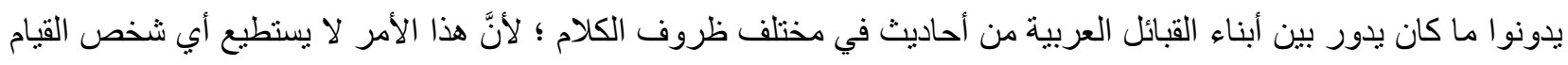

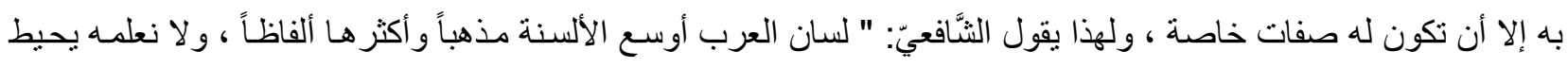

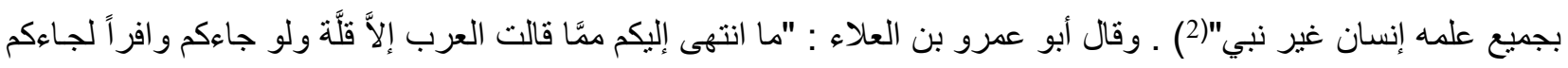

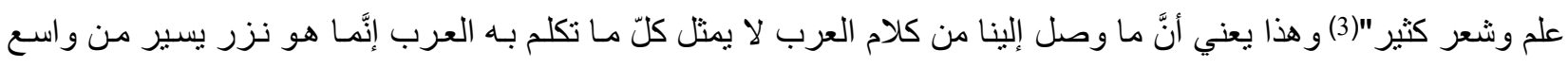

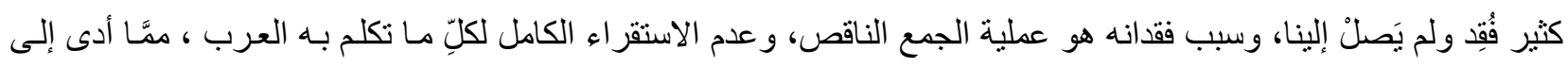
إهمال كثير من الألفاظ و عدم ظهور ها في المعجمات العربية.

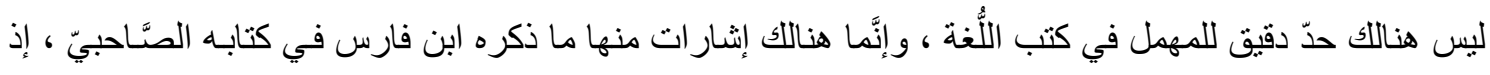

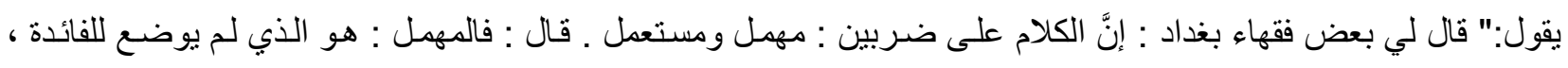

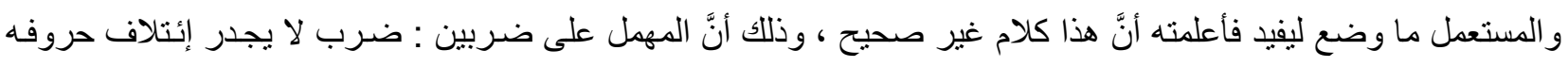

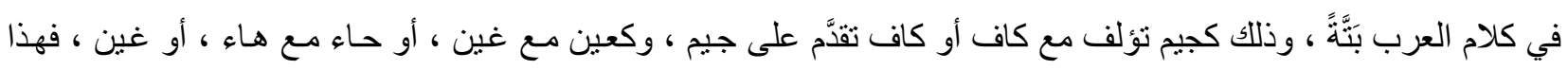
وما أنشبهه لا يأتلف.

و الضَّرب الآخر ما يجوز تألُف حروفه لكن العرب لم تقل عليه وذلك كار ادة مريد أن يقول : (غضخ) فهذا يجوز

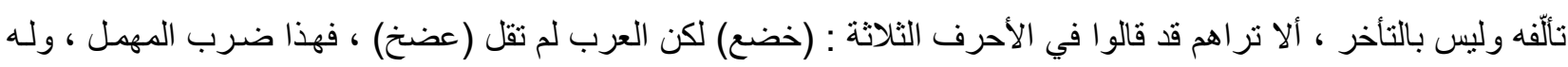

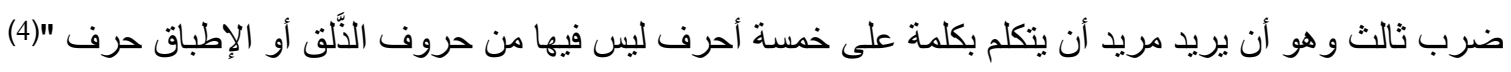

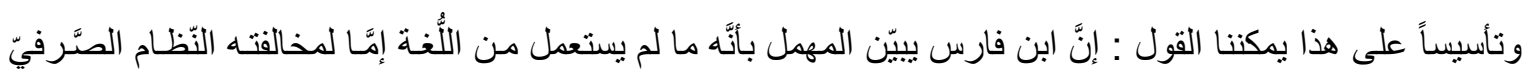

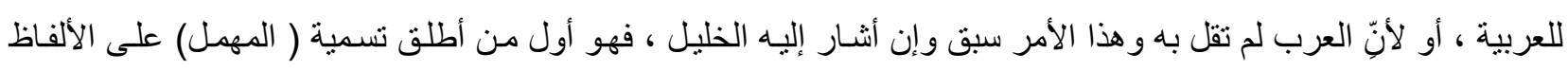

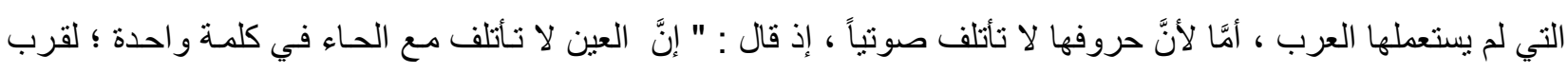

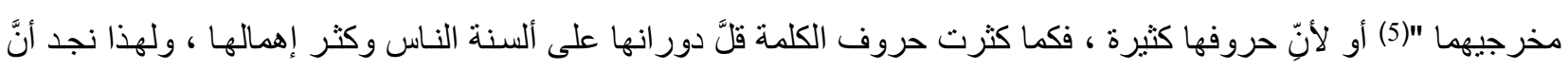

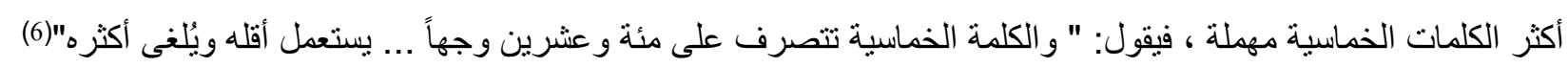




\section{عند استقر ائنا لمعجم مقاييس اللُّة لابن فارس تبين لنا أنَّ المهمل عنده على أنواع هي :}

1. مهمل مقصود: هو الذي أهمله ابن فارس عن قصد منه لأسباب عديدة ، وهذا النَّع من المهمل ينقسم على أقسام هي :

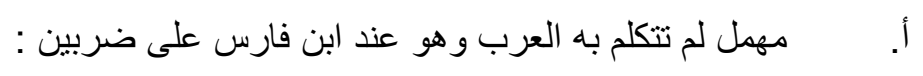

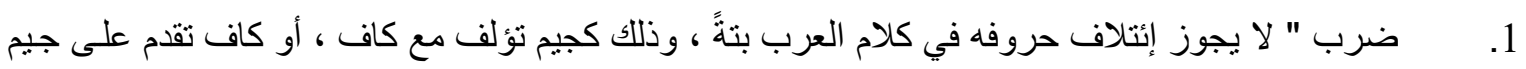

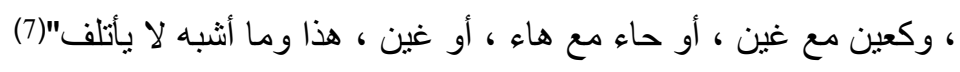

2. ضرب " يجوز تآلف حروفه لكن العرب لم تقل به "(8)

إنَّ هذا الضرب من المهمل ليس له سبب واضتح سوى أنَّ العرب لبساطة حياتهم اليومية وقلة مـا فيها من حاجـات

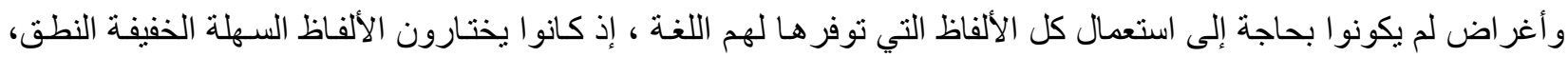

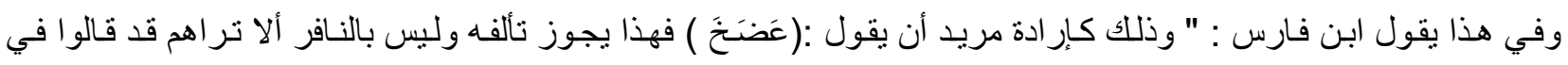

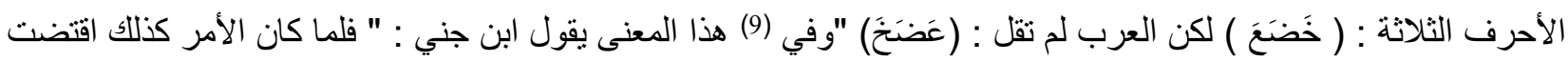

الصورة رفض البعض واستعمال البعض وكانت الأصول ومو اد الكلم معرضة لهم و عارضة النفسها على تخير هم " (10)

$$
\text { ب. نوع تكلمت به العرب لكن ابن فارس لم يذكره ، وهو ينقسم على : }
$$

1. جذور أهماها بأكملها ولم يذكر عليها شيء سوى قوله : " حفس الحاء والفاء والسين ليس أصلا ، يقال

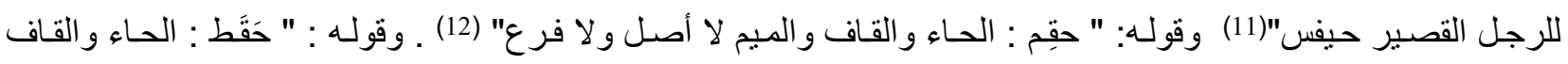

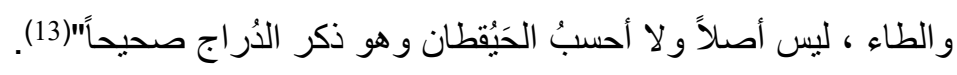

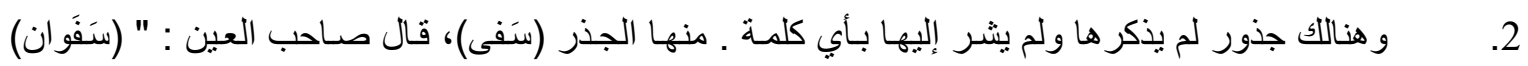

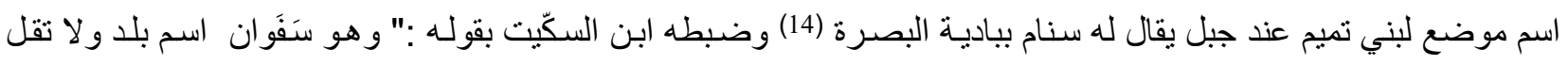

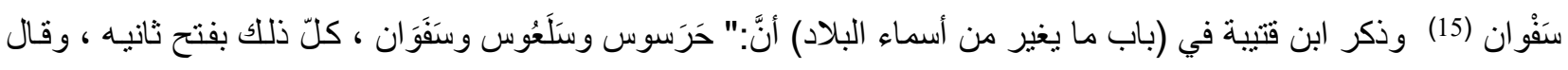

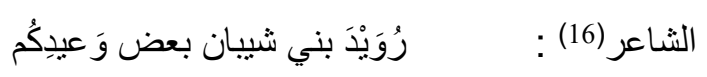

تلاقوَا غدًا خيلي على سَفَوان "(17)

3. ألفاظ ومشتقات ، ذكر جذرها ولكنه أهملها عند كلامـه عن الجذر ، نحو قوله :"زحم الز اءو والحاء و الميح

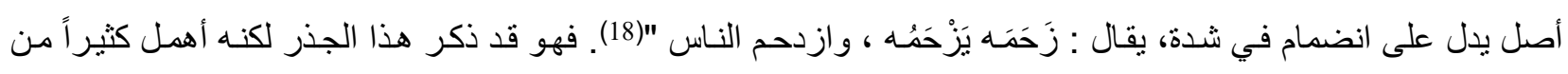

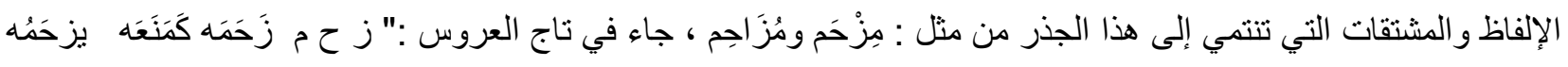

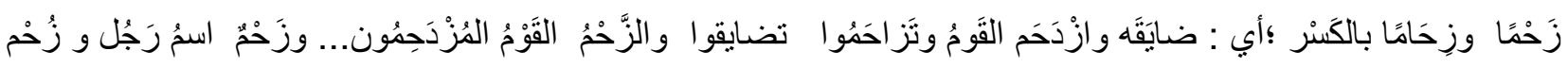

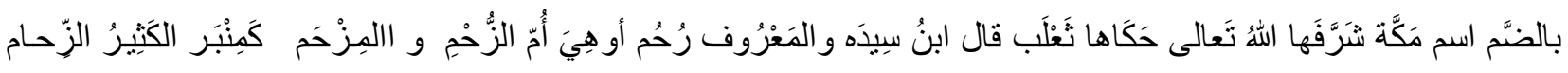

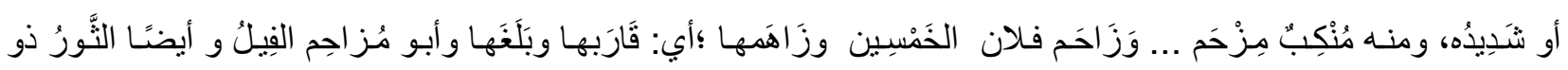

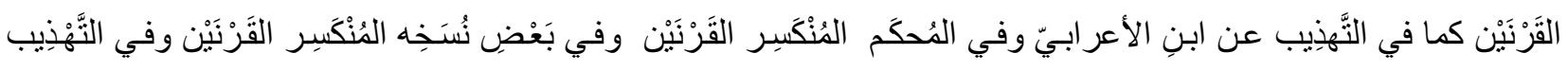

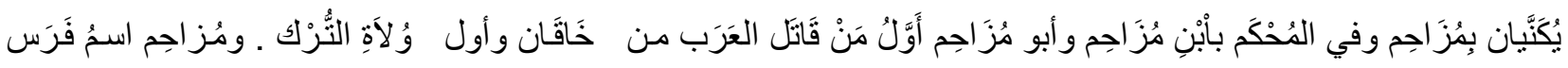

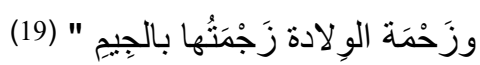

4. دلالة من دلالات لفظ مستعمل ، أهملها ولم يثبتها ثانياً. مهمل غير مقصود 
للمهمل عند ابن فارس أسباب كثيرة يمكن تقسيمها على نوعين :

$$
\text { 2. }
$$

أمَّا لأسباب التي تتعلق باللغة فهي التي ذكرت آنفاً ، و أمَا الأسباب التي تتعلق بجامعيّ اللُّة فيمكن إجمالها بالآتي: 1. سعة لغة العرب ، الأمر الذي يجعل من الإلمام بها أمر اً صعباً بل مستحيلاً ولهذا قـال ابن فـارس : " قـال

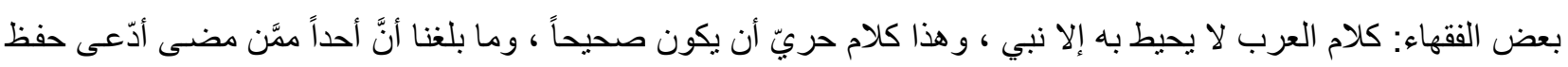
اللُغة كلها ، فأمَّا الكتاب المنسوب إلى الخليل وما في خاتمنه من قول: (هذا آخر كلام العرب ) فقد كان الخدان الخليل أورع و وأتقى لله جلَّ ثناؤه من أن يقول ذلك" (20) 2. اتنساع جغر افية القبائل العربية ، الأمر الذي جعل تتبع أفراد القبائل التي يحتج بكلامها ومشـافهة كل عربي

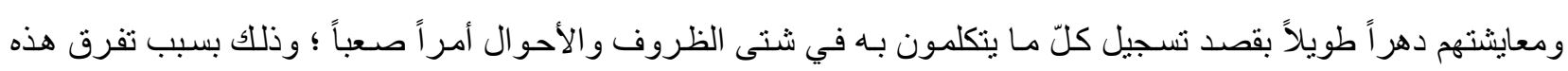

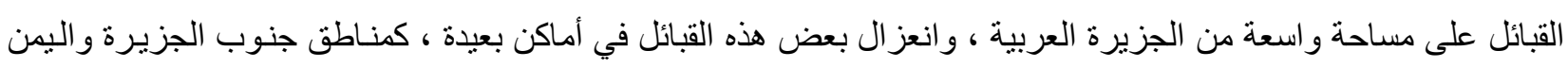

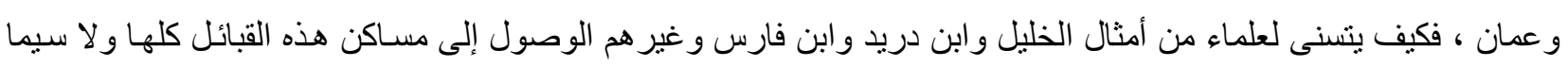

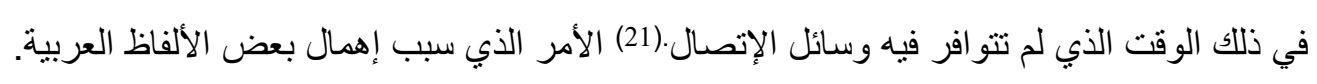

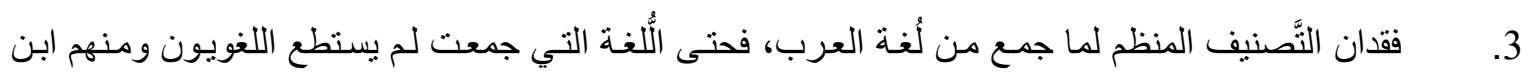

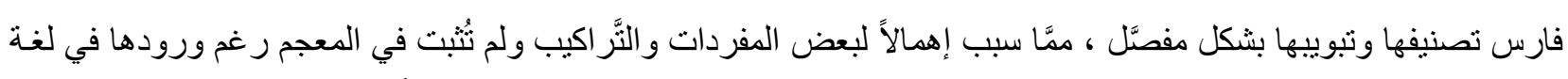

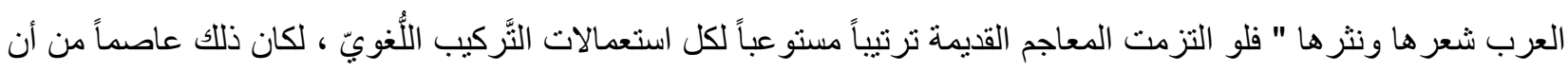

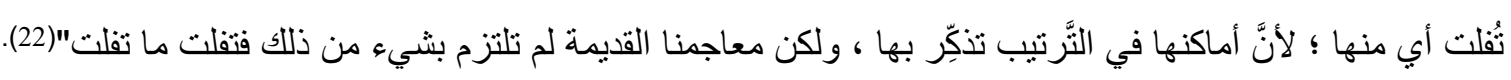

$$
\text { 4. }
$$

وضع اللُغويون شروطاً للألفاظ التي دونوها في معاجمه وهي أن تتو افر فيها معايير الفصاحة ، وهذه المعايير تتأتى بطريقين: الأوَّل : زماني : فلا يُعدّ اللفظ فصيحاً صحيحاً إلا إذا كان في إطار عصور الاحتجاج التي تمتد حتى منتصف القرن

$$
\text { الثاني الهجريّ في الحضر وأواخر القرن الرابع في البادية. }
$$

الثَّاني : مكانيّ : إذ قصر اللُّويون أخذ مادتهم اللُّوية على بعض القبائل العربيـة ، وفي مقدمتها قريش وتميم وأسد

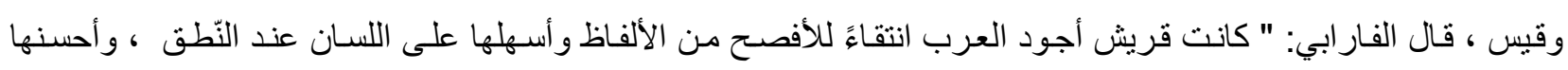

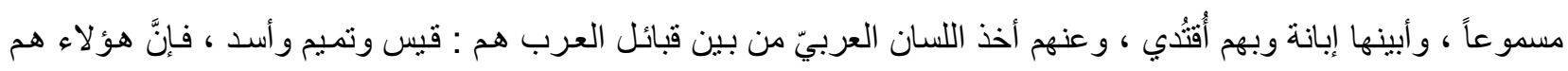

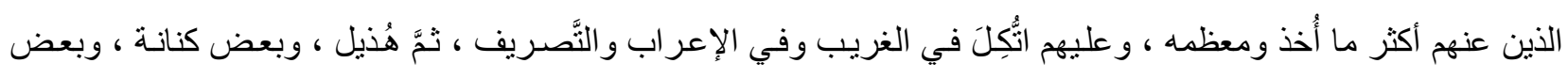

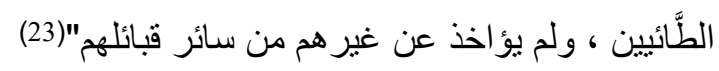
و هذان المعيار ان الزَّمانيّ و المكانيّ جعلا علماء اللُّة يتوقفون كثير اً عن تدوين اللُّذة وجعلاهم يتشددون كثير اً في

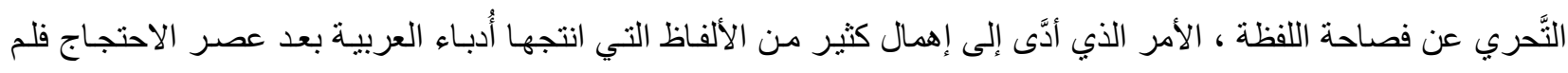
تدون في المعاجم ، رغم أنَّ أكثر ها كان على وفق الامري أصول الصى الأخذ العربية. 


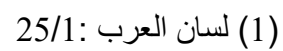

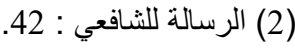

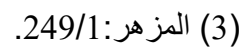

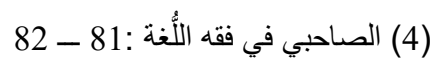

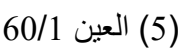

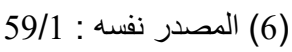

(7) (7) الصاحبي في فقه اللغة : 82.

(8) (8) المصدر نفسه :82)

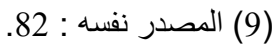

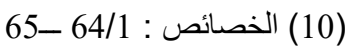

(11) (11) مقاييس اللغة: 256

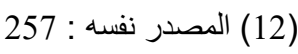

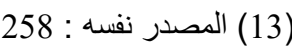

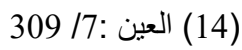

194 : 194 (15) إصلاح المناعن :(14)

127/1 الثاعر : ودًاك بن نُميل المازني. شرح ديوان الحماسة للمرزوقي

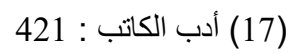

(18) (18) مقاييس اللغة : 449.

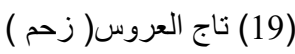

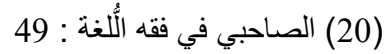

(21) ينظر: الاستندراك على المعاجم العربية: 17.

(22)

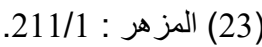

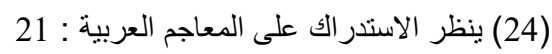

المصادر:

1. أدب الكاتب، ابن قتيبة الدينوري؛ أبو محمد عبدالله بن مسلم بن قتيبة الكوفي المروري الدينوري ، تحقيق : محمد محي الدين عبد الحميد، طه، مصر،1963م

2. الاستنر الك على المعاجم العربية ،د. محمد حسن جبل ، دار الفكر العربي، القاهرة (د.ت).

3. إصلاح المنطق ، ابن السكيت؛ أبو يوسف يعقوب بن إسحاق ، تحقيق : أحمد محمد شاكر و عبد السلام محمد هارون ،ط4 ، القاهرة ، 1949

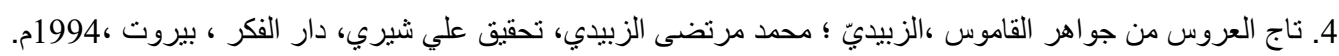

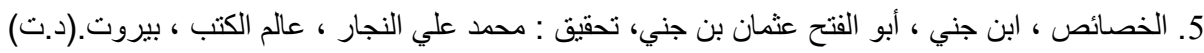

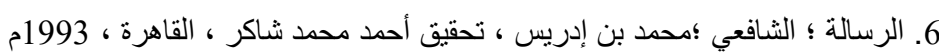

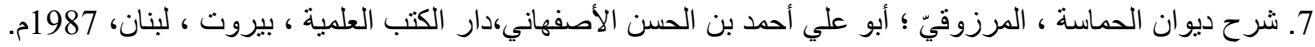

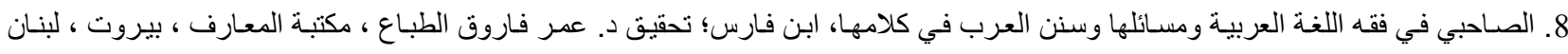
1993،

9. العين ، الفر اهيدي ، الخليل بن أحمد الفراهيدي .تحقيق : مهدي المخزومي وإيراهيم السامر ائي، دار ومكتبة الهلال ـ (د.ت)

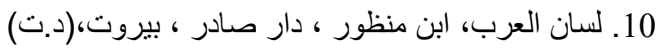

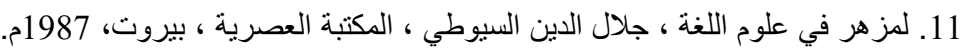

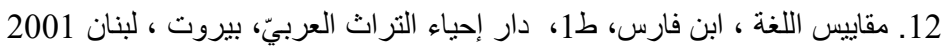

